\title{
Effect of education on preference of parenteral nutrition for patients in palliative care unit: quantitative and qualitative study with an anthropological approach
}

\author{
Ki-Sun Jung ${ }^{1}$, So Yeon Oh ${ }^{1,2}$, Hyun Jung Jun ${ }^{3}$, Byung-Ki Song ${ }^{4}$, Kwonoh Park ${ }^{1,2}$, Sangbo Oh ${ }^{1}$, \\ Jae-Joon Kim ${ }^{1}$, Eun-Ju Park ${ }^{2}$ \\ ${ }^{1}$ Department of Internal Medicine, ${ }^{2}$ Hospice and Palliative Care Team, Pusan National University Yangsan Hospital, Yangsan, Korea; ${ }^{3}$ Department \\ of Internal Medicine, Seoul Medical Center, Seoul, Korea; ${ }^{4}$ Researcher of Medical Ethics, Seoul National University Hospital Biomedical Research \\ Institute, Seoul, Korea \\ Contributions: (I) Conception and design: All authors; (II) Administrative support: HJ Jun, SY Oh; (III) Provision of study materials or patients: HJ \\ Jun, SY Oh; (IV) Collection and assembly of data: SY Oh, BK Song; (V) Data analysis and interpretation: KS Jung, SY Oh, K Park, S Oh, JJ Kim, EJ \\ Park; (VI) Manuscript writing: All authors; (VII) Final approval of manuscript: All authors. \\ Correspondence to: So Yeon Oh, MD. Associate Professor, Medical Oncology and Hematology, Department of Internal Medicine, Pusan National \\ University Yangsan Hospital, 20, Geumo-ro, Yangsan, Korea. Email: manic2db@gmail.com.
}

Background: Patients and their family have resistance in withholding parenteral nutrition (PN) when patient become unable to intake food in the end-of-life. We aimed to investigate whether the preference for $\mathrm{PN}$ is changed after receiving an individual education about the risk and benefit of PN. Additionally, we focused on the preferences of patients and their family and why they prefer it about the nutritional support in the end of life.

Methods: This is prospective study. Patients are eligible if they cannot tolerate oral intake and enteral feeding and have Palliative Performance Scale (PPS) $\leq 50 \%$ due to progressive cancer. After informed consent, investigators educated patients and family for an hour using the handouts. Then, patients decided if they will receive PN. Quality of life (QOL) was checked by European Organization for Research and Treatment of Cancer Quality of Life Questionnaire (EORTC QLQ-C15-PAL) weekly during 3 weeks. Symptoms related to fluid overloading or dehydration was surveyed weekly also. A social anthropologist participated as an observer or interviewer during whole process of this study.

Results: After education, 12 patients (80\%) chose to keep receiving PN and 3 patients (20\%) changed their decision from $\mathrm{PN}$ to minimal hydration among the 15 patients. More calories were administered to patients who chosen $\mathrm{PN}$ (median 1,042.2 vs. $324.3 \mathrm{Kcal} /$ day, $\mathrm{P}<0.001$ ) for initial 7 days. Overall survival, scores of QLQ-C15-PAL, and symptoms were not different with or without PN. According to the anthropologist, medical staffs regard PN as complex medical treatments, while patients and family recognize it as meal rather than medicine.

Conclusions: Most patients and family prefer to receive PN despite its potential harm and marginal benefit. An in-depth discussion about prognosis and aim of care must be preceded before a decision whether to receive $\mathrm{PN}$ can be made.

Keywords: Hospice care; palliative care; parenteral nutrition (PN); patient education; patient preference

Submitted Jan 20, 2020. Accepted for publication Jul 31, 2020.

doi: 10.21037/apm-20-269

View this article at: http://dx.doi.org/10.21037/apm-20-269

$\wedge$ ORCID: 0000-0002-2562-9257. 


\section{Introduction}

It is natural process that a cancer patient cannot eat food when the disease gets worse and gets closer to the end of life. Apart from that fact, patients and their families feel hard to accept or understand that patients cannot eat well again. It is a part of routine medical practice to administer parenteral nutrition $(\mathrm{PN})$ to patients who cannot tolerate oral or enteral nutrition. PN administration may help improve clinical outcome in critically ill patients (1). However, accumulating evidences suggests that PN does not prolong survival periods of advanced cancer patients who cannot tolerate oral and enteral feeding at the end of life (1-4). On the other hand, some data support the supply of PN by improving the patient's quality of life (QOL) and performance status in some advanced cancer patients $(5,6)$. Thus, there is still controversy about administering $\mathrm{PN}$ in advanced cancer patients. Actually, many physicians administer PN to patients with advanced cancer in real practice (7).

Previously, we conducted a randomized phase II trial to assess the effectiveness of fluid therapy or intensive nutritional support on survival in patients with advanced cancer who cannot be nourished via enteral route (8). The study ended prematurely because many patients and families had resistance in withholding $\mathrm{PN}$ when the patient became unable to intake food. Median survival period was not statistically different (8 days in fluid group vs. 13 days in $\mathrm{PN}$ group, $\mathrm{P}=0.982$ by log-rank test).

Therefore, we designed this study focusing on the preferences of patients and their family about the nutritional support in the end of life. We aimed to investigate whether the preference of patients or families for $\mathrm{PN}$ is changed after receiving an individual education about the possible risk and benefit of $\mathrm{PN}$. Additionally, we tried to investigate the preferences of patients and their family and why they prefer it about the nutritional support in the end of life. A social anthropologist participated as an observer or an interviewer during whole process of this study before the consent. He interviews patients, family members and medical staffs in an anthropological approach to find out the real reason for making such a decision about the artificial nutrition.

We present the following article in accordance with the MDAR reporting checklist and Checklist of MORECare Statement (available at http://dx.doi.org/10.21037/apm-20269).

\section{Methods}

This is pilot study to investigate prospectively whether the preference of patients' or families for $\mathrm{PN}$ is changed after receiving an individual education about the possible risk and benefit of PN. Study was performed in Hospice and Palliative care Unit of Seoul Medical Center from March $1^{\text {st }}$ of 2014 to $31^{\text {st }}$ of December of 2014.

\section{Patients}

Patients are eligible if they: (I) are aged $\geq 20$ years old, (II) cannot tolerate oral and enteral feeding, (III) have Palliative Performance Scale (PPS) $\leq 50 \%$ due to progressive cancer. Patients are excluded if they: (I) have any possibility of improvement of cancer, (II) have functioning bowels (can tolerate enteral nutrition via feeding tube or ostomies), (III) have serious electrolyte imbalance that is expected to lead to life-threatening if not corrected immediately.

\section{Study procedure}

The scheme of the study is presented as Figure 1. Eligibility was screened within 14 days from admission to palliative care unit. If patient sign consent, investigators educate patients and family for about an hour using the handouts that describes the risk and benefit of artificial nutrition in end-of-life. Then, patients and family had enough time to discuss each other and with investigators. Within 24 hours from education, they met the investigator again and notified about the decision whether to receive or not to receive $\mathrm{PN}$. PN arm received ready-to-use $\mathrm{PN}$ solution, fluid arm received crystalloid or dextrose water fluid. When they made the choice, we changed (or maintained) the prescription immediately according to the decision about PN. Study continued until patients' death or withdrawal of consent. At the time of consent, we measure height and weight of patient and collect the latest results of complete blood test and biochemical test to determine nutritional status. The anthropologist visited palliative care unit 2 weeks in advance and provided fellowship with unrelated conversations about the subject of nutrition with patients, families and medical staffs. Then, after a trust relationship is formed, they talked about the artificial nutrition. Anthropologists organized the contents and informed research team. The protocol was approved by the institutional review boards of Seoul Medical Center 


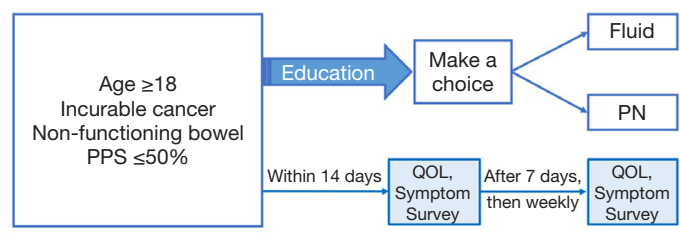

Figure 1 Scheme of the study. Participants are randomized within 14 days from admission to palliative care unit. Then, education and discussion were performed by study staff with patient and families. After decision about whether to receive PN, QOL and symptom were surveyed every 7 days until patient's death. PN, parenteral nutrition; QOL, quality of life; PPS, Palliative Performance Scale.

(No. SMC2014-002) and performed in accordance with the principles of the Declaration of Helsinki (as revised in 2013) and the Good Clinical Practice Guidelines defined by the International Conference on Harmonization. All patients provided written, informed consent before enrollment.

\section{Study end points}

The primary end point is to determine the changes in preference of patients and families for PN or fluid supply by education about artificial nutrition and hydration of endof-life. Secondary endpoints are: (I) QOL that was checked by EORTC QLQ-C15-PAL weekly until $3^{\text {rd }}$ weeks, (II) severity of symptoms related to fluid overloading or dehydration was surveyed by Seoul MC-PAL-Q7-PN weekly (see Figure S1), and (III) the content of interview by anthropologist. EORTC QLQ-C15-PAL consists of four domains; three items of physical functioning, two items of emotional functioning, nine items of symptom scale, one global QOL item. The result was summarized according to scoring manual $(9,10)$. The questionnaire Seoul MC-PALQ7-PN consists of seven items that can be answered on four Likert scales about severity of each subjective symptoms. Each item describes the following symptoms: (I) abdominal distension, (II) vomiting or reflux symptom, (III) sense of phlegm stuck in throat, (IV) edema of limbs, (V) fatigue, (VI) sense of hunger, (VII) drying of mouth and throat. The items 1 through 4 refer to symptoms associated with overhydration, while items 5-7 refer to dehydration-related symptoms. The questionnaire was analyzed by comparing the sum of items 1 to 4 and the sum of 5 to 7 at each visit as converted to 100 points. The higher score means more severe symptom. Additionally, total administered calorie per days was calculated during the first week per each patient from the next day of decision.

\section{Statistical analyses}

The demographic and clinical parameters are analyzed by descriptive statistics. The symptom survey and the administered calorie for initial 7 days in two arms were compared by Mann-Whitney $U$ test as they had nonparametric distribution. Overall survival was analyzed by Kaplan-Meier survival analysis and compared using logrank test. The mean value of QOL score and symptom score were compared by Student's $t$-test. All statistical analyses were conducted using Microsoft Excel 2013 and SPSS version 21.

\section{Results}

Total 22 patients met eligibility criteria. Among them, 18 patients and their families agreed to participate study and signed informed consent. The baseline characteristics of participants are presented at Table 1 . The median age is 72.5 (44.1-88.2) years. In anthropometric data, patients had considerably low body mass index (BMI). At the time of consent, 15 patients (83.3\%) are receiving $\mathrm{PN}$ and three patients are receiving within 1-liter fluid (Figure 2).

\section{Patients' choices about PN}

The change of preference of patients' or families for PN after receiving an individual education about the possible risk and benefit of $\mathrm{PN}$ is presented at Figure 2. Twenty percent $(n=3)$ of patients and their families (group A2) changed their mind from receiving $\mathrm{PN}$ to fluid only by education. Consequently, 12 patients (A1) chose to keep receiving $\mathrm{PN}$ and six patients $(\mathrm{A} 2+\mathrm{B})$ received only fluid administration. Regarding the insight about the prognosis, nine patients $(75 \%)$ among the group A1 recognized that they are in terminal state. In group A2 and B, all 6 patients had complete awareness about their disease stage and prognosis. When we look closely at the three who changed their minds in group A2, one of them is a 82-year-old female patient with gastric cancer had complete insight about prognosis said, "I have done all I have to do in my life, and I want to go naturally because I have no regrets anymore". Another 62-year female patient with colon cancer said, "It is beartbreaking to break up with my family, but I am afraid that maybe I will extend a painful period". The last one, 88-yearold male patient with gastric cancer could not speak and his 
Table 1 The baseline characteristics of participants

\begin{tabular}{|c|c|}
\hline Characteristics & Value \\
\hline \multicolumn{2}{|c|}{$\begin{array}{l}\text { Demographic, clinical } \\
\text { characteristics, n (\%) }\end{array}$} \\
\hline Total number & $18(100.0)$ \\
\hline \multicolumn{2}{|l|}{ Sex } \\
\hline Male & $6(33.3)$ \\
\hline Female & $12(66.7)$ \\
\hline \multicolumn{2}{|l|}{ Type of cancer } \\
\hline Colon/rectum & $6(33.3)$ \\
\hline Stomach & $5(27.8)$ \\
\hline Pancreas & $2(11.1)$ \\
\hline Genitourinary & $2(11.1)$ \\
\hline Biliary & $1(5.6)$ \\
\hline Breast & $1(5.6)$ \\
\hline Lung & $1(5.6)$ \\
\hline \multicolumn{2}{|l|}{ PPS } \\
\hline $50 \%$ & $7(38.9)$ \\
\hline $40 \%$ & $3(16.7)$ \\
\hline $30 \%$ & $8(44.4)$ \\
\hline \multicolumn{2}{|c|}{ Anthropometric data, mean $( \pm S D)$} \\
\hline Height, cm & $157.9( \pm 7.0)$ \\
\hline Weight, kg & $50.6( \pm 10.7)$ \\
\hline $\mathrm{BMI}, \mathrm{kg} / \mathrm{m}^{2}$ & $20.2( \pm 3.6)$ \\
\hline
\end{tabular}

PPS, Palliative Performance Scale; BMI, body mass index.

eldest son decided to stop PN reflecting the patient's intent to avoid meaningless medical procedures.

\section{QOL and symptom scale}

The QOL was evaluated using EORTC QLQ-C15-PAL. Overall, there were many missing data because many participants were unable to answer the questionnaire due to poor general condition. In the result of each domains of the EORTC QLQ-C15-PAL, the global health scale, physical and emotional functioning were not different according to study groups (with or without PN) (see Figure S2). The summary of symptom survey reflecting fluid overloading or dehydration symptom (Seoul MC-PAL-Q7-PN) was presented at Table S1. Generally, dehydration-related

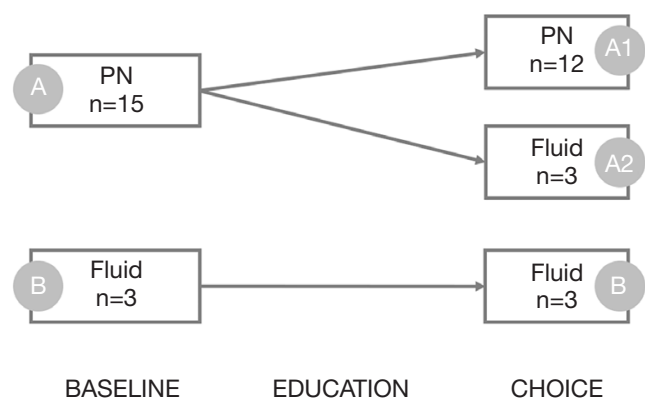

Figure 2 Patients' choice at baseline and after education. At the point of consent, 15 patients (group A, 83.3\%) are receiving $\mathrm{PN}$ and 3 patients (group B) are receiving less than 1 liter of $5 \%$ dextrose water. After education, 12 patients (group A1, 80\%) chose to keep receiving $\mathrm{PN}$ and 3 patients (group A2, 20\%) changed their decision from $\mathrm{PN}$ to minimal hydration among the group $\mathrm{A}$. All of the group B patients did not want to receive PN still. PN, parenteral nutrition.

symptom (fatigue, sense of hunger, and drying of mouth and throat) was more severe than overhydration-related symptom in every study day. The symptoms between two groups are not significantly different at all study days.

\section{Administered calories and survival}

The total administered calories during initial 7 days from the next day of decision were calculated. In PN arm, median value of total calories administered per patients for a day was $1,042.15$ and $324.30 \mathrm{Kcal} /$ day in fluid arm. The difference was statistically significant $(\mathrm{P}<0.001$, MannWhitney $\mathrm{U}$ test). The overall survival for all patients was 21 (95\% CI: 7.1-34.9) days. According to PN administration, the median survival was $21 \pm 5.2$ days in the $\mathrm{PN}$ arm and $13 \pm 9.2$ days in fluid arm $(\mathrm{P}=0.910$, log-rank test). The Kaplan-Meier plot of survival in two groups was presented at Figure 3.

\section{Anthropologist's report and contents of representative interview}

\section{Anthropologist's report}

The family caregivers and patients were greatly influenced by visuality of PN fluid. They perceived the PN bag and infusion line as an object to confirm that the patient was connected to somewhere (food supply). This phenomenon 


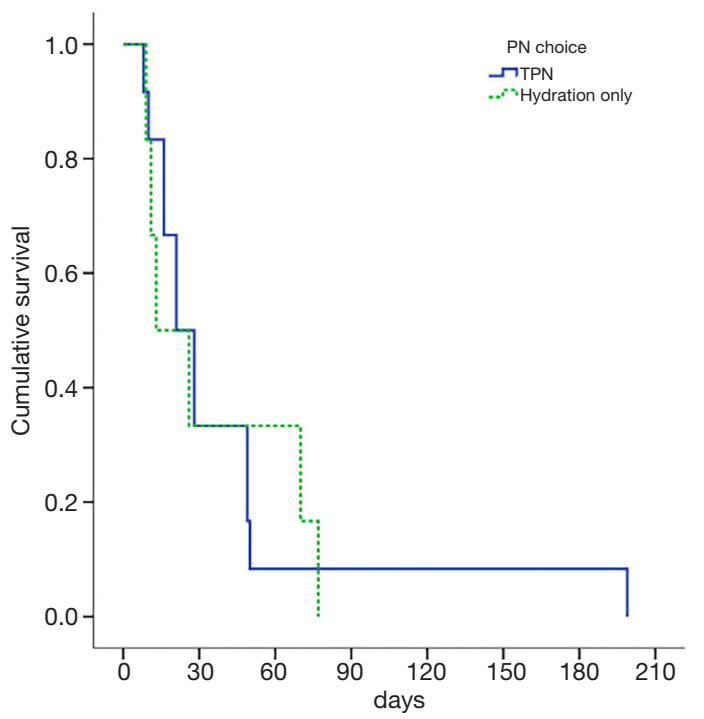

Figure 3 Kaplan-Meier survival curves according to artificial nutrition choices. One patient in PN group survived more than 6 months. The median survival was not statistically different between two groups $(\mathrm{P}=0.910, \log$-rank test $)$. $\mathrm{PN}$, parenteral nutrition.

can be called "funnel theory"; the conclusion is always the same regardless of the evidence and the logical reasoning. If the condition of patient is fair, they thought it is by virtue of PN. On the contrary, if condition were bad, they thought patients should receive PN to improve condition. Most of them also accept hospice as a treatment and think that if it fails, they die. Their idea of "good death" is mainly "go comfortably without pain". This method of recognition can serve as a reason for not giving up PN until just before death. If there is a clear perception of hospice, though small in number, $\mathrm{PN}$ is recognized as a meaningless treatment and rejected. In reality, where most modern people's dying places are hospitals and medical facilities, hospitals are mistaken for "vacuum medical spaces". Rather, the hospital is a mixed space where rituals, acts, and values are mixed in the home where the death was experienced before. The representative statements of patients, families, and medical staffs are introduced below.

\section{Patients' statement}

Many patients had strong confidence in PN fluid and relied on it. One 62-year-old man with colon cancer said that " $I$ think that (PN fluid) is not a kind of medical treatment. That is a meal replacement". Another 76-year-old lady with head and neck cancer believed that PN was prolonging her life. She disclosed that "I think, PN is prolonging my life. Though it causes some troublesome symptoms, I want to keep receiving that. However, if my cancer symptoms are not improved, I would stop the PN and go bome to die".

\section{Families' statement}

They thought it was cruel to inform their loved one that we would stop PN. A wife of 58-year-old male patient spoke that "It is too cruel to tell him (patient) that I will going to cease his meal. I can't do that". Many families did not want to discuss about ceasing $\mathrm{PN}$ with patient because they were afraid to inform the patient about the life expectancy.

\section{Medical staffs' statement}

One resident doctor stated that "Intravenous administration of fluid or PN is specialized medical treatment. We need regular blood test for safe use of PN to monitor electrolyte imbalance or metabolic abnormalities related to PN. It may cause or aggravate undesirable symptom like reflux in patient with bowel obstruction". A regular nurse said that "Patients and caregivers are assured that a white liquid (means lipid-containing $P N$ ) is connected to the body. It seems they equate it with cooked rice".

\section{Discussion}

This study tried to investigate whether individual education can change patients and families' preferences about artificial nutrition in end of life. Education for an hour could not completely change patients' preferences for PN. However, about $20 \%$ changed their mind from PN to simple hydration after education. Length of survival and QOL were not different with or without PN. Insight into their disease status and prognosis and understanding about the goal of hospice care may be associated with the decision to stop receiving PN. We want to show the possibility that education can change the preference of patients and families for PN by this study. We also tried to look into their true intentions why they would make such a decision. An anthropological approach helped us to find their minds without patient-doctor interactions.

There is no firm data supporting the artificial nutrition and hydration at the end of life of advanced cancer patients (11). Therefore, experts recommend not to give PN to terminally ill patients (3). But on the contrary, subset of patients with advanced cancer certainly exists who derives benefits from PN (12-14). Several studies reported long term survival among patients with good performance status, slowly progressing tumor, and especially who is receiving PN because of gastrointestinal obstruction due to cancer. 
Therefore, the major clinical guidelines recommend that PN supply should be considered only for patients whose survival is expected to be more than a few months $(1,2)$. However, it is very difficult and incorrect to estimate the life expectancy of advanced cancer patients. Thus, whether to or not to give PN to advanced cancer patients is complicated issue to decide.

In previous trial, we failed to meet the target number of patients because many patients and families did not get away from the idea that the patient could starve to death (8). From the failed study, we learned that the decision about $\mathrm{PN}$ on the end of life cannot be determined solely by the medical utility of it, but rather by the emotional or psychological needs of the patients and the families. Therefore, we planned this study to see if we could change the decision about PN by educating patients and caregivers about the role of PN in last days of life. Percentage (20\%) itself may not be accurate because of the small number of this study, but it is clear that some patients have changed their minds not to receiving PN after being educated. Actually, three patients (or family) wanted to stop to be administered $\mathrm{PN}$ after receiving an education. Two of three patients had complete insight to their disease and understand goal of hospice care. Thus, better understanding of the prognosis of the patient's own illness and the goal of hospice care seems to increase the likelihood of choosing not to receive $\mathrm{PN}$.

Surprisingly, according to the anthropologist's report, patients think $\mathrm{PN}$ is a 'liquid meal' rather than a medical treatment. Most of patients and families thought that hospice is a kind of medical treatment and death means a failure of medicine including hospice. Based on this perception, the patients and family cannot accept stopping the PN even in the last days of their life. Investigators found that patients and families need to fully understand the goals and implications of hospice care based on accurate information about disease status and prognosis of the patients so that they can decide whether or not to receive $\mathrm{PN}$. If they do not understand the meaning and purpose of hospice care, they are willing to take PN regardless of the benefit of it although they know the condition and prognosis. Through an anthropological approach, we could hear what patients did not want to say to the medical staff or hospice team. Hospice team members should spend time with their patients and their families to engage in indepth conversations and help them understand the goals of hospice care so that they can make the right decisions by reflecting their wishes.
Our study has several limitations. First, most of participants $(83.3 \%$ ) were already receiving $\mathrm{PN}$ at the time of consent. It may be more likely to be more distressing for the patients and families to withdraw than to withhold the PN. It may have been more painful to stop PN that they already receiving than not to receive from the first time at all. If we educate patients and family immediately after admission, they may more preferred not to receive PN. Second, method of education may not be optimal. We used conventional handouts and short lecture. It may be a better way for patients and families to understand, such as video or mobile platforms that able real-time interactive question and answer, than the traditional lecture method. Additionally, 1 hour may be not sufficient time to fully understand complex medical procedures such as PN. Third, this study was undertaken in palliative care unit of general hospital. This condition makes us difficult to draw universal answer for $\mathrm{PN}$ in hospice setting. The decisions might be different among the patients in the home hospice or independent hospice facility. Fourth, due to time and fund limitation, our population is quite small.

In conclusion, we were convinced that not providing PN in hospice was not the only answer from this study. From the anthropological approach, we found that withholding or withdrawing of $\mathrm{PN}$ is not only a medical problem but also a cultural, humanistic, and psychological decision. Prior to make decision about PN, we should discuss for a sufficient time with patient and families about disease status, prognosis, goal of care, and concerns and wishes of them. Only then we can make the right decision about the artificial nutrition.

\section{Acknowledgments}

The authors thank Hyun Ji Cho, clinical research coordinator at Seoul Medical Center and Mi-Kyung Kang at Pusan National University Yangsan Hospital for helping our data management.

Funding: None.

\section{Footnote}

Reporting Checklist: The authors have completed the MDAR reporting checklist. Available at http://dx.doi.org/10.21037/ apm-20-269

Checklist of MORECare Statement: Available at http://dx.doi. org/10.21037/apm-20-269 
Data Sharing Statement: Available at http://dx.doi. org/10.21037/apm-20-269

Conflicts of Interest: All authors have completed the ICMJE uniform disclosure form (available at http://dx.doi. org/10.21037/apm-20-269). The authors have no conflicts of interest to declare.

Ethical Statement: The authors are accountable for all aspects of the work in ensuring that questions related to the accuracy or integrity of any part of the work are appropriately investigated and resolved. The protocol was approved by the institutional review boards of Seoul Medical Center (No. SMC2014-002) and performed in accordance with the principles of the Declaration of Helsinki (as revised in 2013) and the Good Clinical Practice Guidelines defined by the International Conference on Harmonization. All patients provided written informed consent before enrollment.

Open Access Statement: This is an Open Access article distributed in accordance with the Creative Commons Attribution-NonCommercial-NoDerivs 4.0 International License (CC BY-NC-ND 4.0), which permits the noncommercial replication and distribution of the article with the strict proviso that no changes or edits are made and the original work is properly cited (including links to both the formal publication through the relevant DOI and the license). See: https://creativecommons.org/licenses/by-nc-nd/4.0/.

\section{References}

1. August DA, Huhmann MB; American Society for Parenteral and Enteral Nutrition (A.S.P.E.N.) Board of Directors. A.S.P.E.N. clinical guidelines: nutrition support therapy during adult anticancer treatment and in hematopoietic cell transplantation. JPEN J Parenter Enteral Nutr 2009;33:472-500.

2. Arends J, Bachmann P, Baracos V, et al. ESPEN guidelines on nutrition in cancer patients. Clin Nutr 2017;36:11-48.

3. Dev R, Dalal S, Bruera E. Is there a role for parenteral

Cite this article as: Jung KS, Oh SY, Jun HJ, Song BK, Park K, Oh S, Kim JJ, Park EJ. Effect of education on preference of parenteral nutrition for patients in palliative care unit: quantitative and qualitative study with an anthropological approach. Ann Palliat Med 2020;9(5):2793-2799. doi: 10.21037/apm-20-269 nutrition or hydration at the end of life? Curr Opin Support Palliat Care 2012;6:365-70.

4. Muscaritoli M, Molfino A, Laviano A, et al. Parenteral nutrition in advanced cancer patients. Crit Rev Oncol Hematol 2012;84:26-36.

5. Cotogni P, De Carli L, Passera R, et al. Longitudinal study of quality of life in advanced cancer patients on home parenteral nutrition. Cancer Med 2017;6:1799-806.

6. Vashi PG, Dahlk S, Popiel B, et al. A longitudinal study investigating quality of life and nutritional outcomes in advanced cancer patients receiving home parenteral nutrition. BMC Cancer 2014;14:593.

7. Kim DY, Lee SM, Lee KE, et al. An evaluation of nutrition support for terminal cancer patients at teaching hospitals in Korea. Cancer Res Treat 2006;38:214-7.

8. Oh SY, Jun HJ, Park SJ, et al. A randomized phase II study to assess the effectiveness of fluid therapy or intensive nutritional support on survival in patients with advanced cancer who cannot be nourished via enteral route. J Palliat Med 2014;17:1266-70.

9. Fayers PM, Aaronson NK, Bjordal K, et al. EORTC QLQ-C30 scoring manual. 1999.

10. Groenvold M, Petersen MA; on behalf of the EORTC Quality of Life Group. Addendum to the EORTC QLQ-C30 scoring manual: scoring of the EORTC QLQC15-PAL. 2006.

11. Good P, Richard R, Syrmis W, et al. Medically assisted nutrition for adult palliative care patients. Cochrane Database Syst Rev 2014;(4):CD006274.

12. Chermesh I, Mashiach T, Amit A, et al. Home parenteral nutrition (HTPN) for incurable patients with cancer with gastrointestinal obstruction: do the benefits outweigh the risks? Med Oncol 2011;28:83-8.

13. Fan BG. Parenteral nutrition prolongs the survival of patients associated with malignant gastrointestinal obstruction. JPEN J Parenter Enteral Nutr 2007;31:508-10.

14. Hoda D, Jatoi A, Burnes J, et al. Should patients with advanced, incurable cancers ever be sent home with total parenteral nutrition? A single institution's 20-year experience. Cancer 2005;103:863-8. 


\begin{tabular}{|c|c|c|c|c|}
\hline & Not at All & A Little & $\begin{array}{c}\text { Quite a } \\
\text { Bit }\end{array}$ & $\begin{array}{l}\text { Very } \\
\text { Much }\end{array}$ \\
\hline I feel my stomach is full without eating. & & & & \\
\hline $\begin{array}{l}\text { It is hard because of symptoms of vomiting or frequent } \\
\text { reflux. }\end{array}$ & & & & \\
\hline $\begin{array}{l}\text { It is hard because of the feeling that the phlegm is stuck in } \\
\text { the neck and does not come out well. }\end{array}$ & & & & \\
\hline It is uncomfortable with swelling of arms or legs & & & & \\
\hline I have no energy all day. & & & & \\
\hline I feel hungry. & & & & \\
\hline I feel uncomfortable because my mouth and throat is dry. & & & & \\
\hline
\end{tabular}

Please fill in your name, birthday, and today

Name:

Birthday: (year) (month) (day)

Today's date: (year) (month)

(day)

Figure S1 Seoul Medical Center Palliative Questionnaire 5-parenteral nutrition (Seoul MC-PAL-Q5-PN)*. We are interested in some things about you and your health. Please answer all of the questions yourself by circling the number that best applies to you. There are no "right" or "wrong" answers. The information that you provide will remain strictly confidential. *, This is not the material used in actual study, but is translated into English to help readers understand it. The original form is written in Korean. 

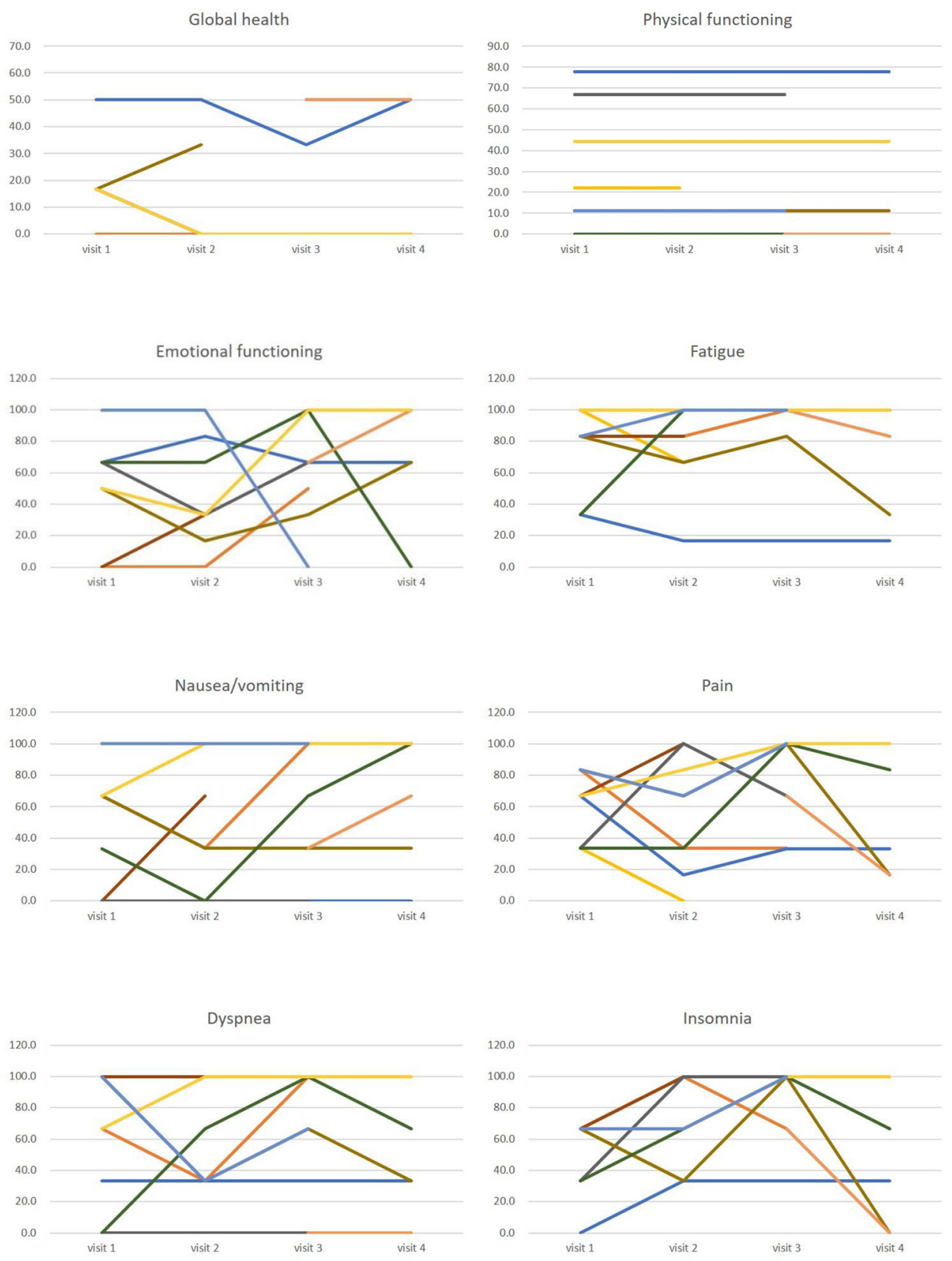

Figure S2 The trend of each domains of EORTC QLQ-C15-PAL over time in all participants shows many participants were unable to answer the questionnaire from the first visit, and even more people were unable to respond to the questionnaire as time passed. There was no sign of difference according to study groups. 
Table S1 The result of Seoul MC-PAL-Q7-PN: summary of symptom survey reflecting over-hydration or dehydration symptoms

\begin{tabular}{|c|c|c|c|c|}
\hline & Visit $1(n=17)$ & Visit $2(n=9)$ & Visit $3(n=8)$ & Visit $4(n=6)$ \\
\hline$P$ value* & 0.799 & 0.333 & 1.000 & 0.800 \\
\hline Dehydration score (median) & 66.7 & 83.3 & 83.3 & 58.4 \\
\hline$P$ value* & 0.799 & 0.677 & 1.000 & 0.800 \\
\hline
\end{tabular}

*, Difference of distribution between two study groups by Mann-Whitney $U$ test. $P$ value less than 0.05 is considered significant. 